\title{
ANMAATUL MANHAJI DIRAASIL LUGHATIL ARABIYAH \\ FIL MADRASATI ATS-TSANAWIYYAH AL ISLAMIYAH AL HUKUMIYYAH AL ULA TULUNG AGUNG
}

$$
\begin{aligned}
& \text { أنحاط المنهج الدراسي للّغة العربية في المدرسة الثانوية الإسلامية } \\
& \text { الحكومية الأولى تولونج أجونج }
\end{aligned}
$$

Ahmad Nurcholis, Anis Zunaidah

IAIN Tulungagung, IAIN Tulungagung

cholisahmad87@gmail.com zunaidah20@gmail.com

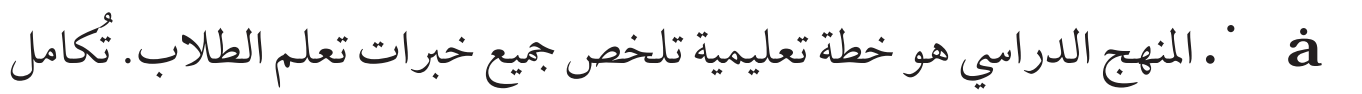

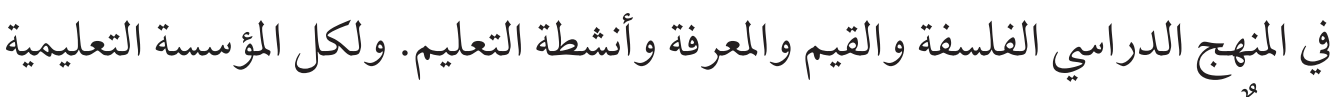

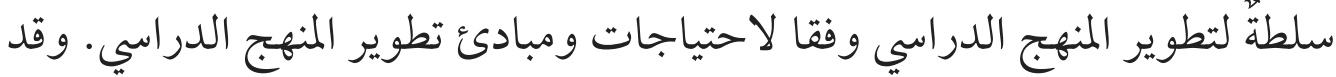

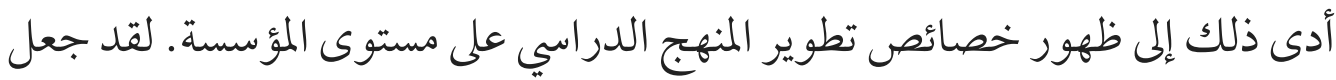
بعض فلاسفة التربية الإسلامية تصنيف فلسفة التربية الإسلامية في عدة الأنماط لأجل التحل

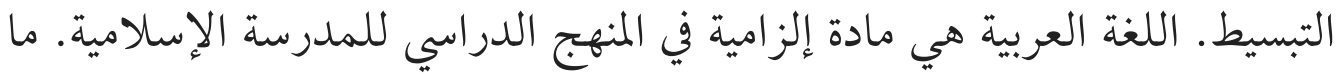

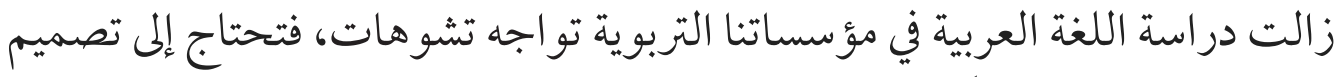

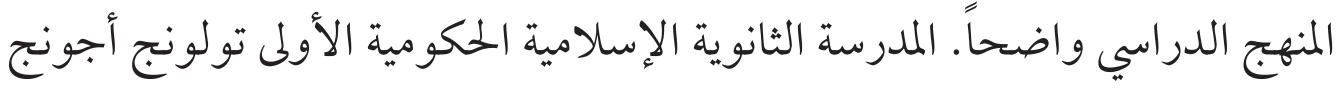

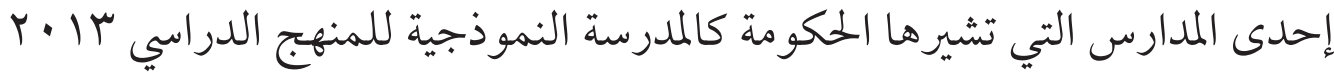

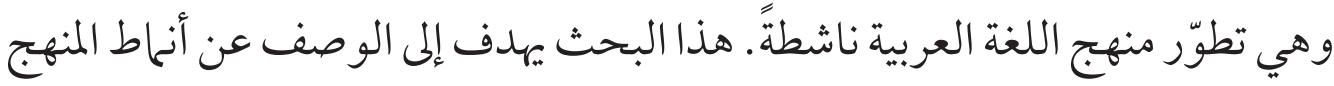

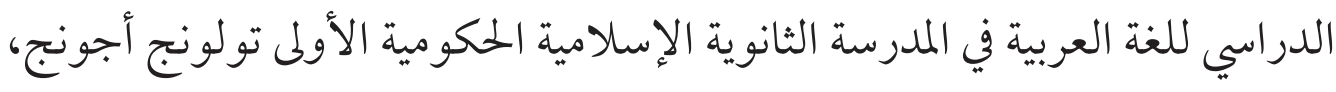

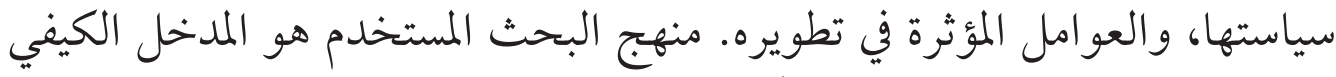

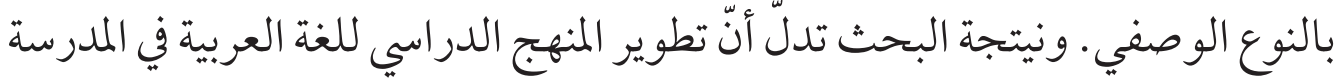

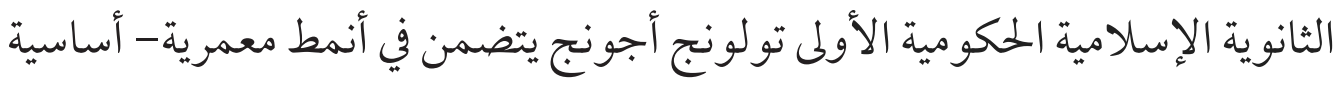
سياقية تحريفية. وهي الطريقة الوسطية للاندماج بين الكلاسيكية والحديثة.

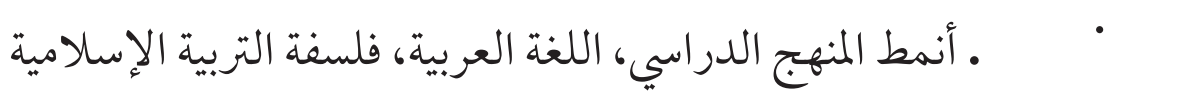




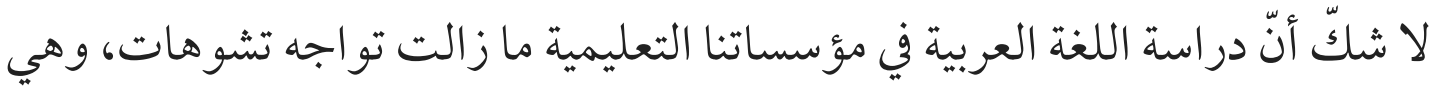

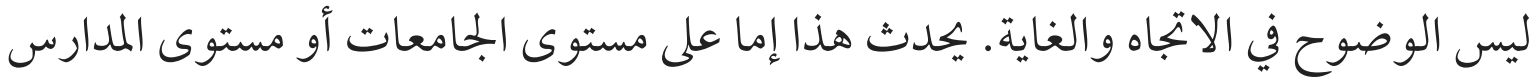

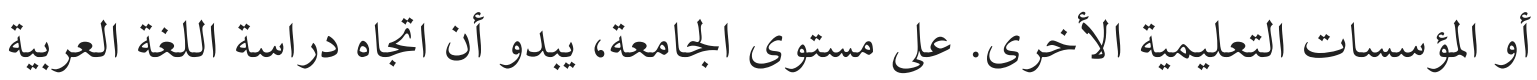

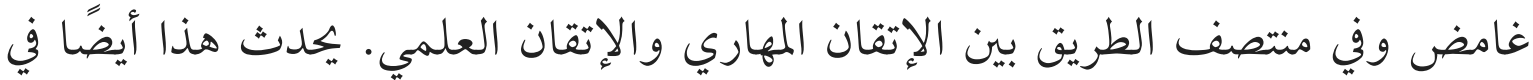
المؤسسات مستوى المدرسة التي تبدو غير مؤكدة.'

وفقا لهيرماوان، يمكن رؤية هذا الغموض في جو انب عديدة. أولاً، من حيث الهدف،

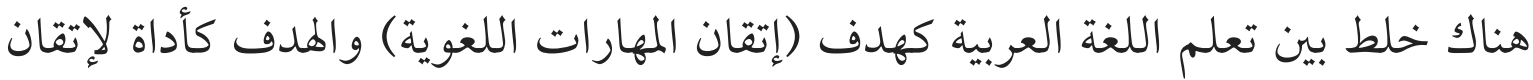

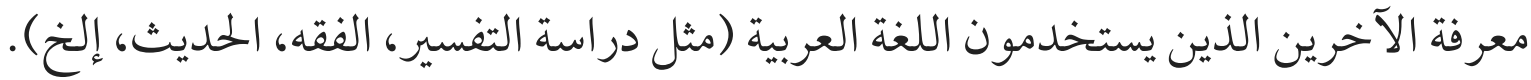

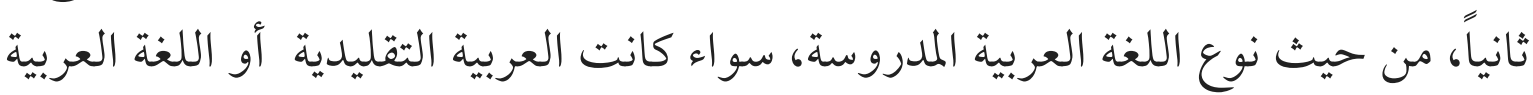

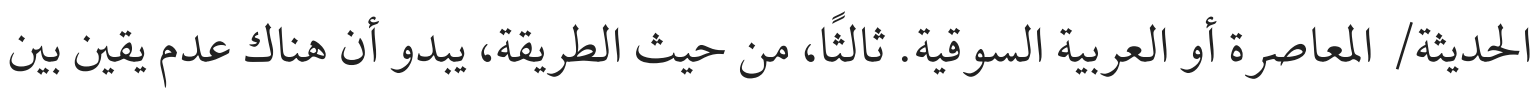
متابعة التطورات والحفاظ على الطريقة القديمة. ؟

فيما يتعلق بهذا الغرض، أي بين الهدف المهاري والهدف المعرفي، فكلاهما لا يمكن

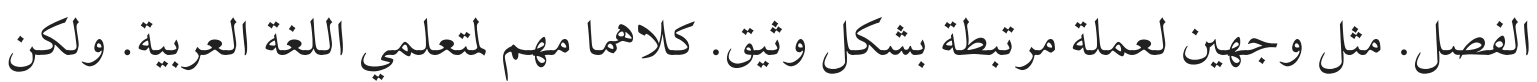

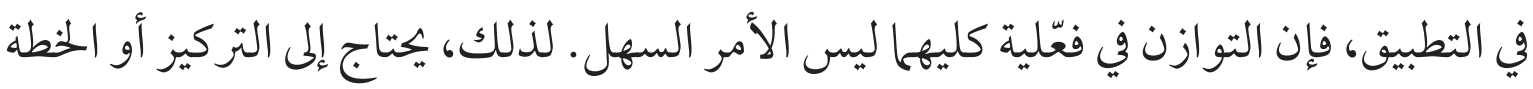

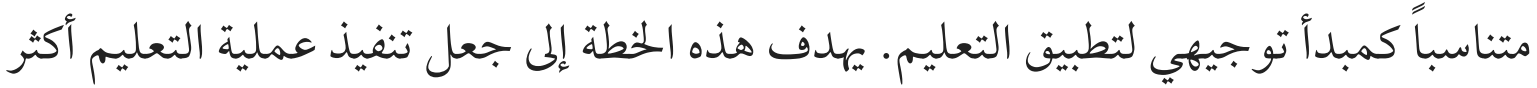
توجهاً ومناسباً بالتو قعات. وتسمى الخطة عادة بالمنهج الدراسي.

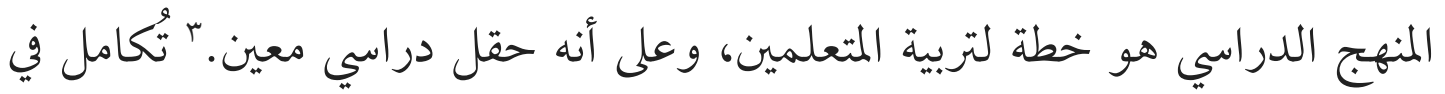

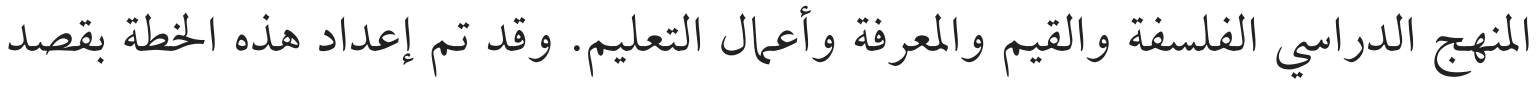

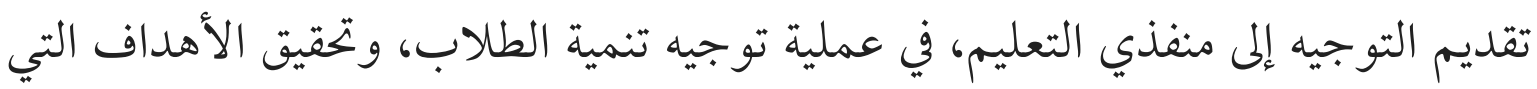

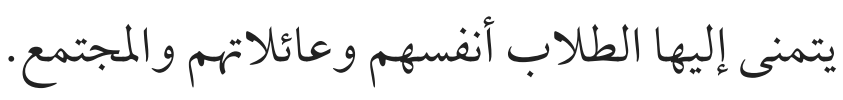
2011), h. 95

1 Acep Hermawan, Metodologi Pembelajaran Bahasa Arab, (Bandung: Remaja Rosdakarya, 2 Ibid., h. 96

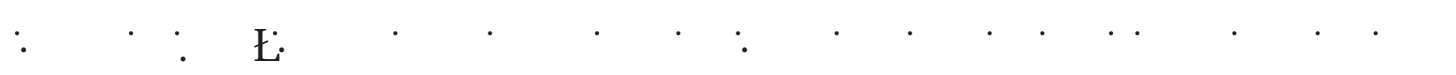

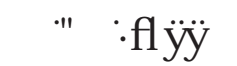


يرتبط الحديث عن قضايا المنهج الدراسي ارتباطًا وثيقًا بالفلسفة. لا يمكن تطوير المنهج

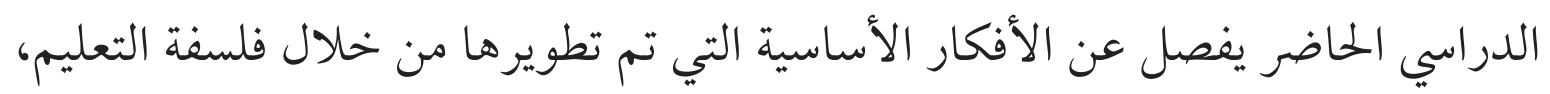

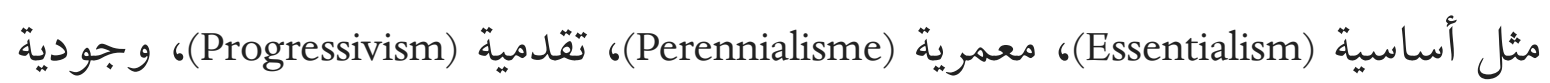

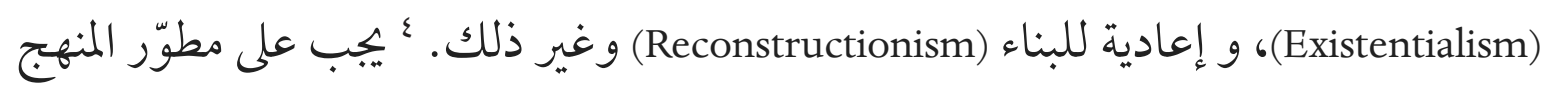
الدراسي في اتخاذ القرارات حول المنهج الدراسي اهتحام إلى الفلسفة، إما الفلسفة الوطنية أو داء فلسفة المؤسسات التعليمية أو فلسفة المدرس.

لقد جعل بعض فلاسفة التربية الإسلامية تصنيف فلسفة التربية الإسلامية في عدة

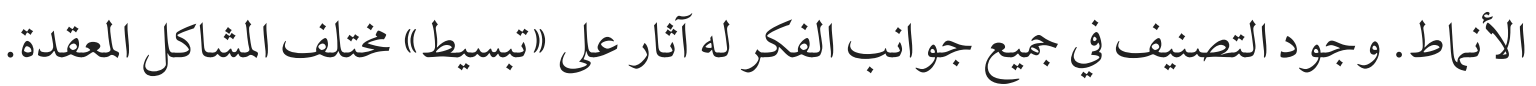

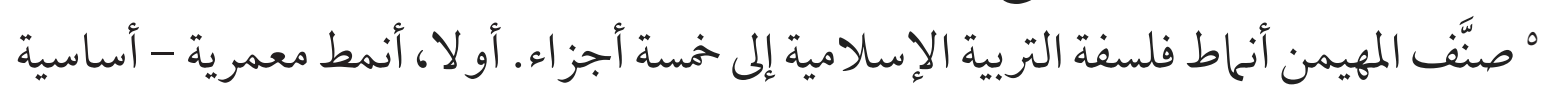
سلفية (Perenial-Esensialis Salafi). يمكن تصنيف هذا النموذج كنموذج معمري نصّي سلفي وفي وقت واحد أساسي نصي سلفي. المعامل من معمري نصّي سلفي هو طبيعته الارتدادية

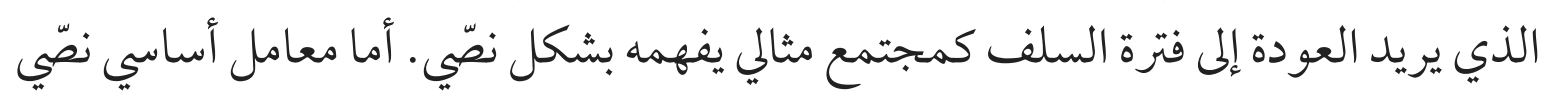

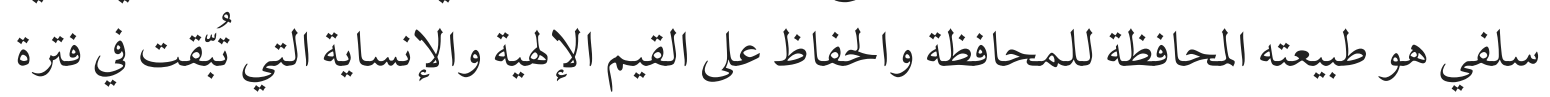

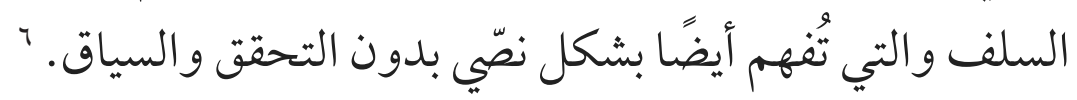

ثانيا، أنحاط معمرية-أساسية مذهبية (Perenial-Esensialis Mazhabi). يبرز بناء الأنمط

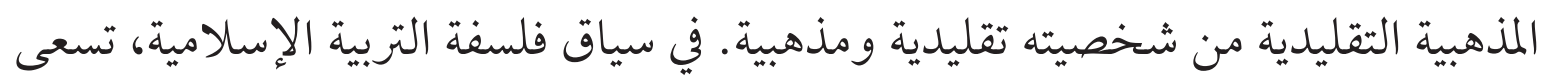

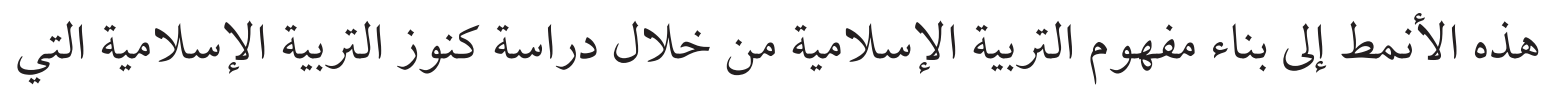

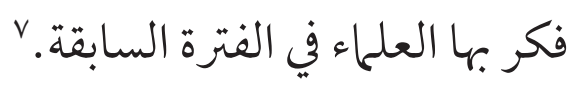

ثالثا، أنماط حداثية (Modernis). تؤكد هذه الأنمط لفلسفة التربية الإسلامية معرفةً

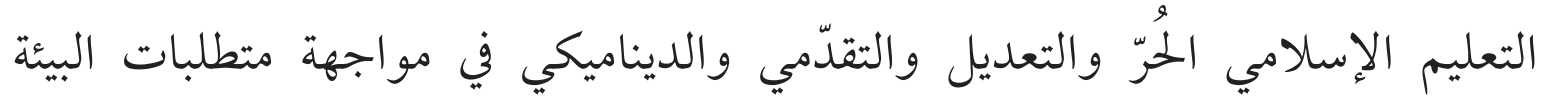

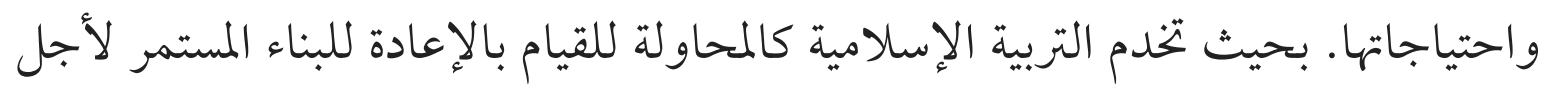

4 Moch. Tholchah, "Filsafat Pendidikan Islam: Konstruksi Tipologis dalam Pengembangan Kurikulum" dalam Jurnal Tsaqafah vol. II no. 2, November 2015, (Gontor: Unida, 2015), h. 382

5 Ibid. Lihat pula Bani Achmad, "Tipologi Filsafat Pendidikan Islam dan Implementasinya dalam Pengembangan Kurikulum" dalam jurnal Edukasi vol. 02 no. 01, Juni 2014, (Tulungagung: STAI Muhammadiyah, 2014), h. 426

6 Muhaimin, Pengembangan Kurikulum Pendidikan Agama Islam di Sekolah, Madrasah, dan Perguruann Tinggi (Jakarta: Rajawali Pers, 2005), h. 89-112

7 Ibid. 
الذكاء و القدرة على التكيف بالمتطلبات واحتياجات في الوقت الحاضر.^

Perenial-Esensialis Kontekstual) رابعا، أنماط معمرية-أساسية سياقية تحريفية

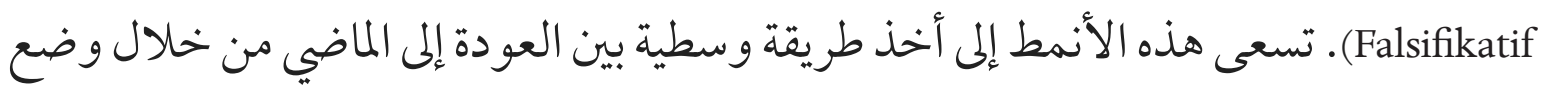

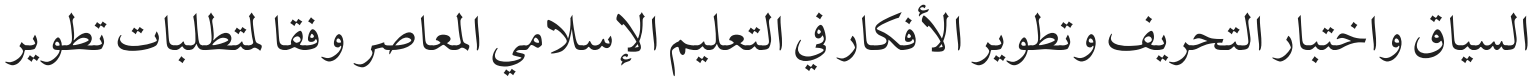

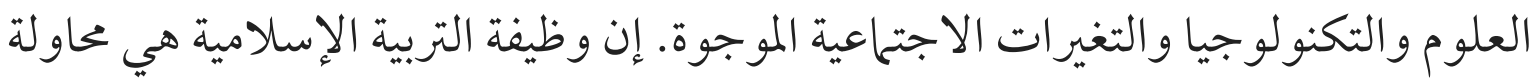

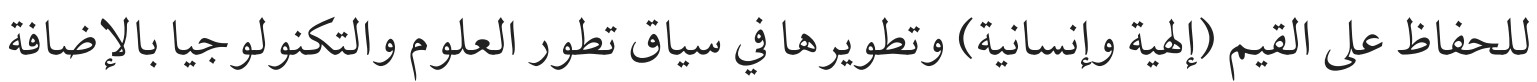
إلى التغيرات الاجتماعية الموجودة.

خامسا، الأنماط التي تعود إلى البناء الاجتماعي على أساس التوحيد Rekonstruksi)

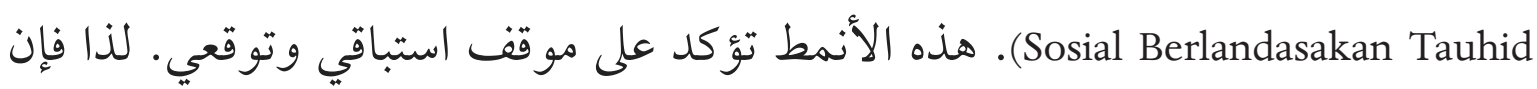

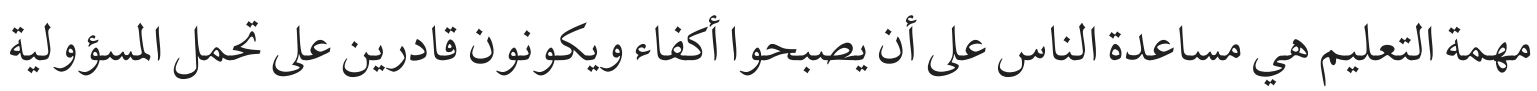

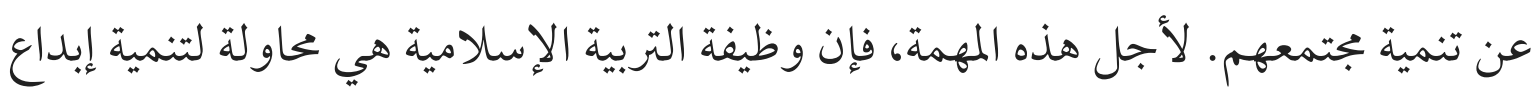
الطلاب، وإثراء كنوز الثقافة البشرية، وإثراء محتويات القيم الإنسانية والإلهية، وإعداد

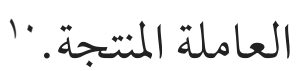

سيؤدي عدم الوضوح في اتجاه تطوير المنهج الدراسي إلى عدم تحقيق الأهداف المتوقعة.

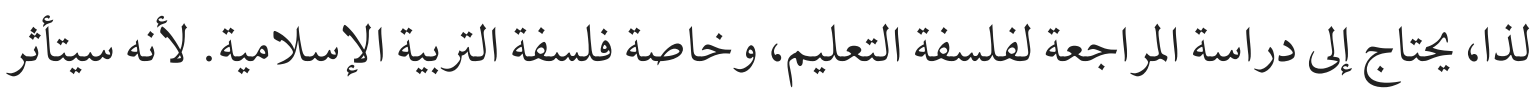
على تطوير المنهج الدراسي في المؤسسة.

إنّ لكل المؤسسة التعليمية رؤيت ورسالة. وذلك وفقا لما يهدف أن تتأسّس المؤسسة.

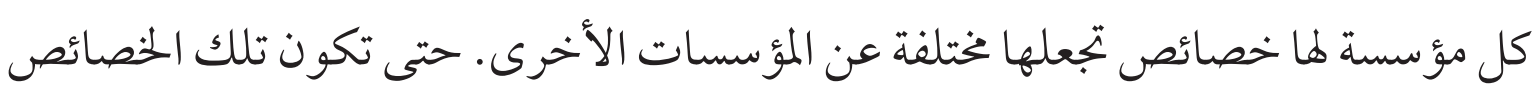

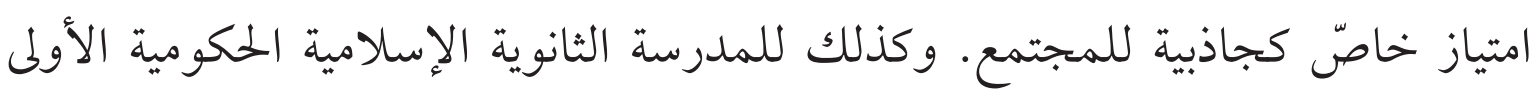
تولونج أجونج.

السبب الذي يجعل الباحثان يختار ان المدرسة الثانوية الإسلامية الحكومية الأولى تولونج أجونج كمكان للبحث هو أن هذه المدرسة ناشطة في تطوير المنهج الدراسي للغة العربية ولها 
أنمط أو خصائص خاصة تميزها عن المؤسسات التعليمية الأخرى. وبالتالي، تعيّن الخكومة

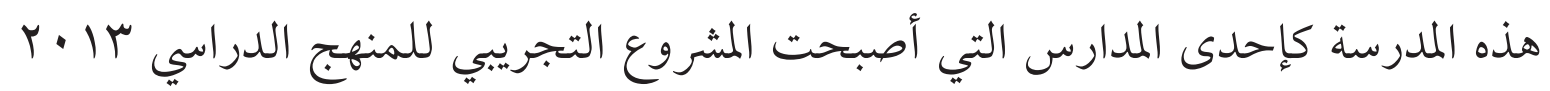

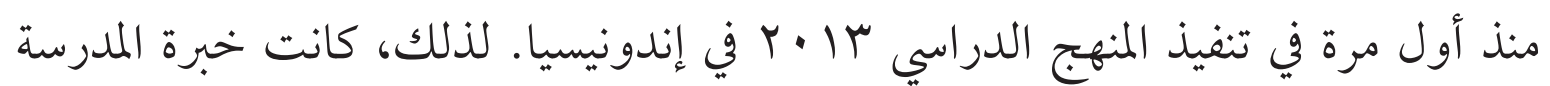

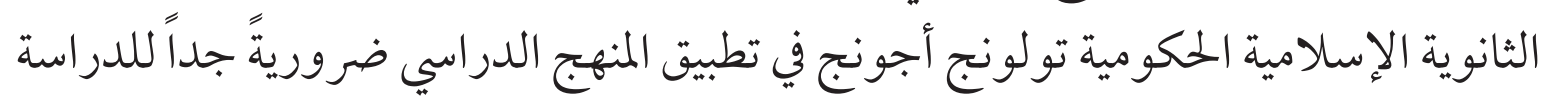
وللبحث.

استناداً إلى الشرح المذكور، يريد الباحثان لبحث تطوير المنهج الدراسي للغة العربية في

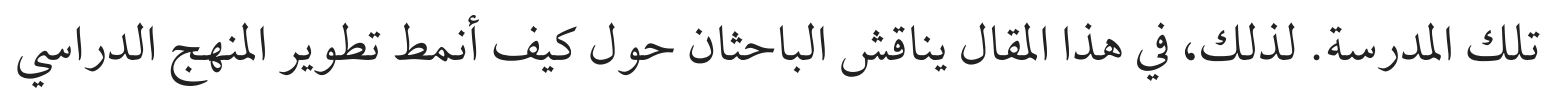

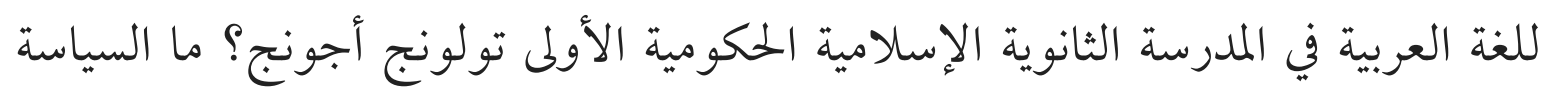

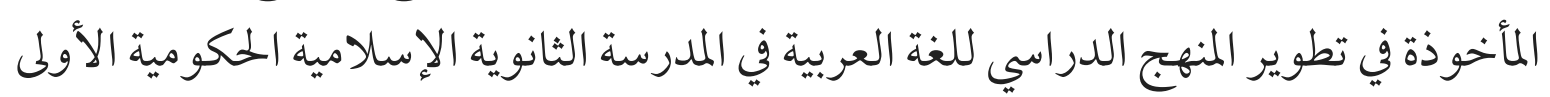

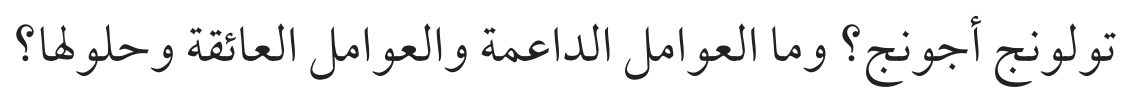

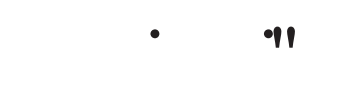

بالنظر إلى المشكلات المذكورة السابقة، استخدم الباحثان مدخلاً كيفياً بنوع البحث الوصفيّ.

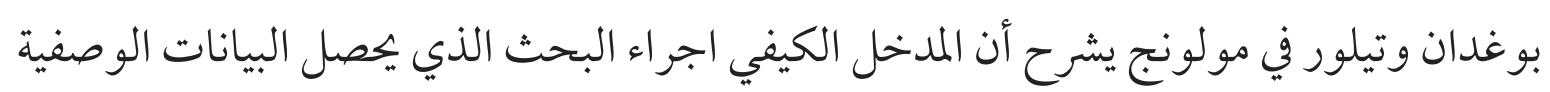

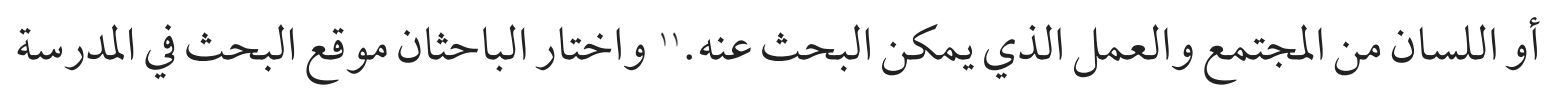

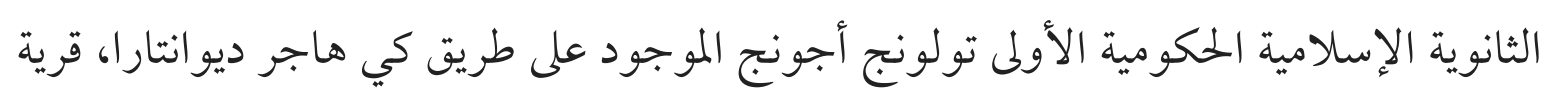

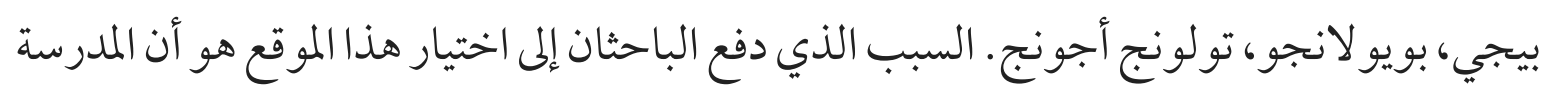

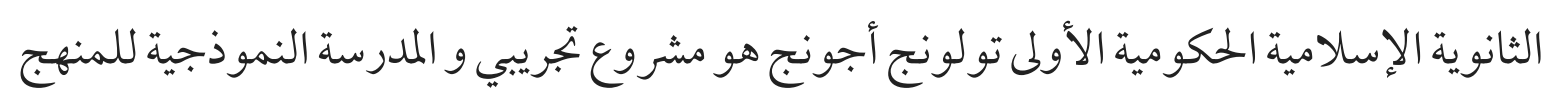
الدراسي با • r. . وهي تطوّر المنهج الدراسي لمادة الغة العربية ناشطةً.

في هذا البحث هناك نوعان من مصادر البيانات، وهما مصدر أولويّ ومصدر ثانوي. بات

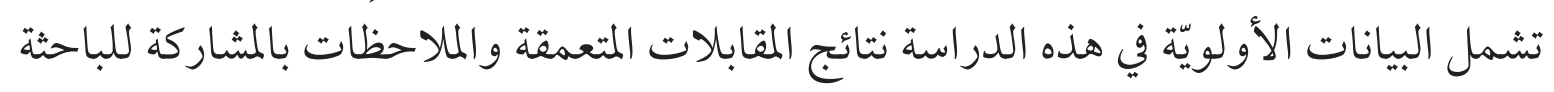
مع معلمي اللغة العربية والطلاب ومساعد الرئيس للمنهج و وأما البيانات الثانوية في هذه الدراسة

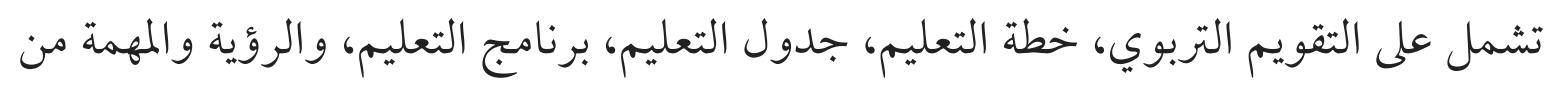

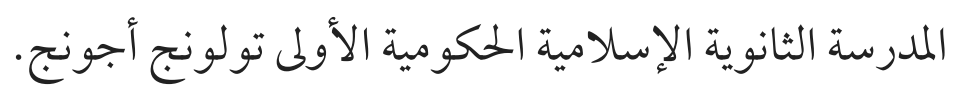

11 Lexy J. Meleong, Metodologi Penelitian Kualitatif, (Bandung: Remaja Rosdakarya, 2011), h. 4 12 Saifudin Azwar, Metode Penelitian, (Yogyakarta: Pustaka Pelajar Offset, 2002), h. 91 
طريقة جمع البيانات في هذا البحث تستخدم ثلاث طرق وفقًا لما قدمه بوغدان وبيكلن،

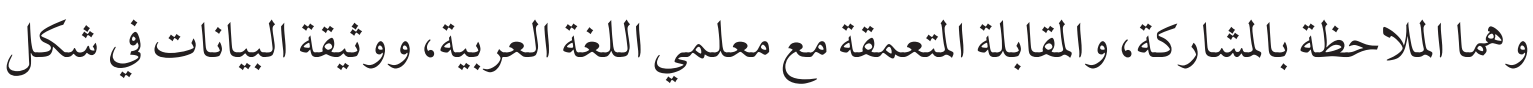

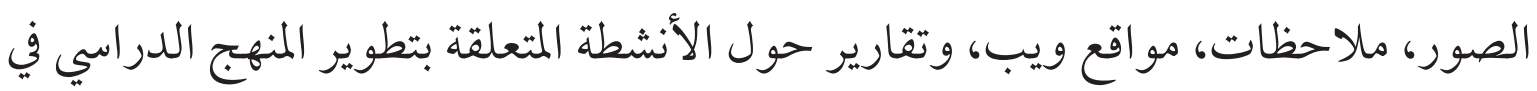

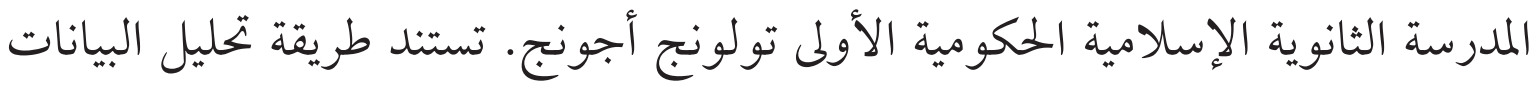

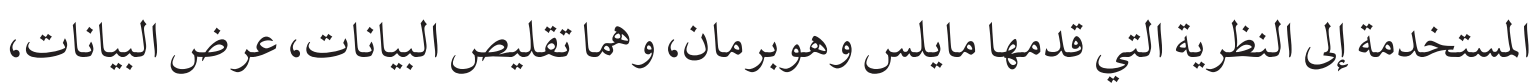

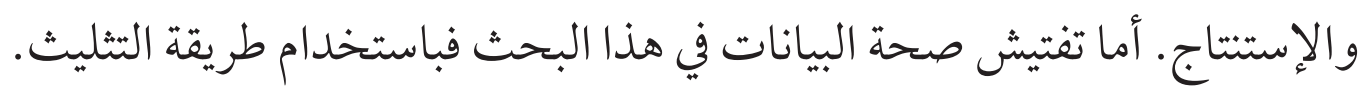

\section{Td解}

1. أنمط المنهج الدراسي للغة العربية في المدرسة الثانوية الإسلامية الحكومية الأولى تولونج أجونج

المدرسة الثانوية الإسلامية الحكومية الأولى تولونج أجونج إحدى المدارس الإسلامية

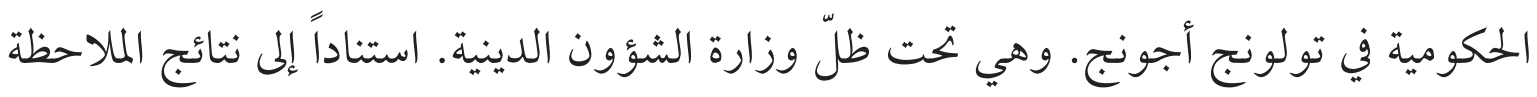

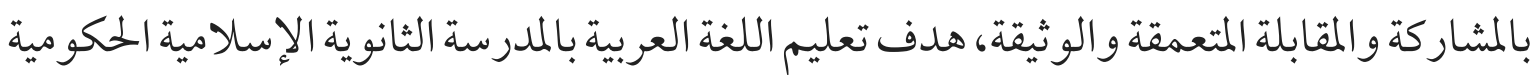

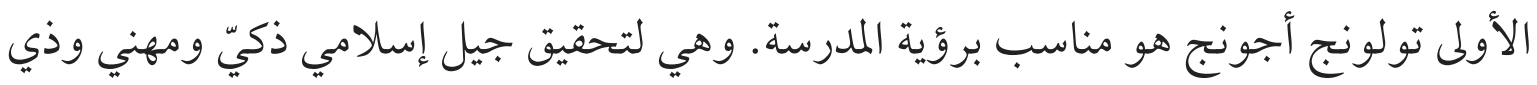

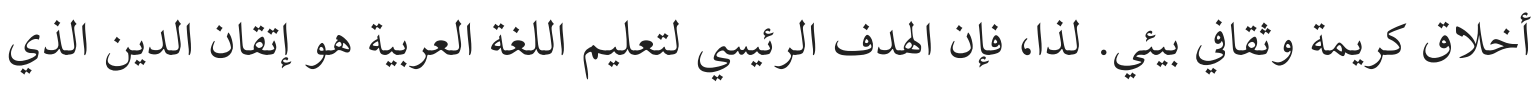

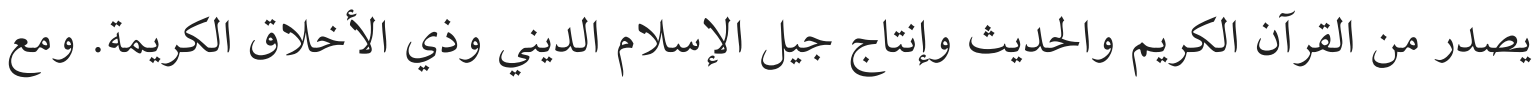
ذلك، من ناحية أخرى، فإنه لا يستبعد وظيفة اللغة العربية كأداة الاتصال.

وبذلك، تكون أنمط تطوير المنهج الدراسي للغة العربية في المدرسة الثانوية الإسلامسة الثانس

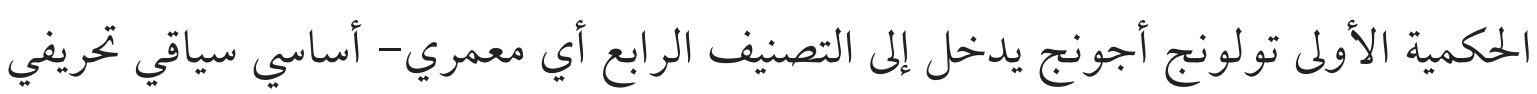
(Perenial-Esensialis Kontekstual Falsifikatif)

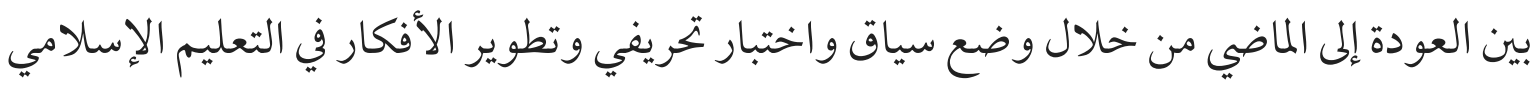

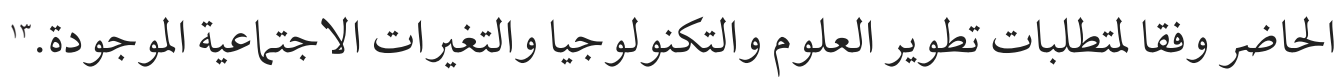

من هنا، يمكن أن نفهم أن المدرسة الثانوية الإسلامة الحكومية الأولى تولونج أجونج الإنجا

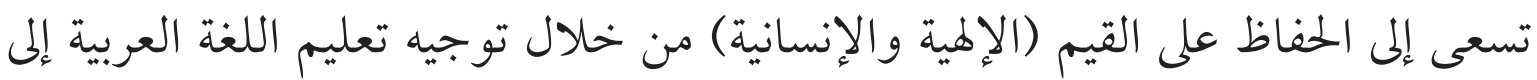


الفهم الديني وإلى إنتاج جيل ذي أخلاق كريمة. ولكن من ناحية أخرى، من ناحية أخرى، الخها،

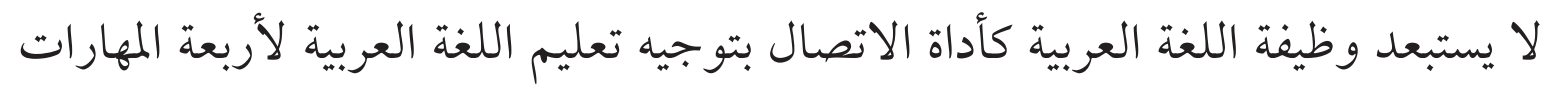

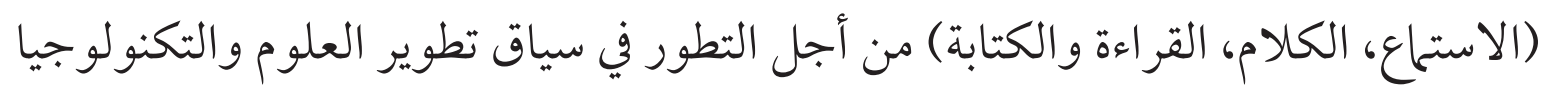

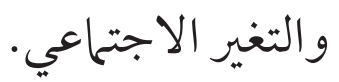

بالنظر إلى تطوير المادة، تندمج المدرسة الثانوية الإسلامية الحكومية الأولى تولونج

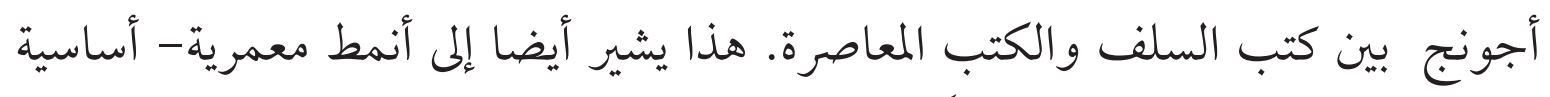

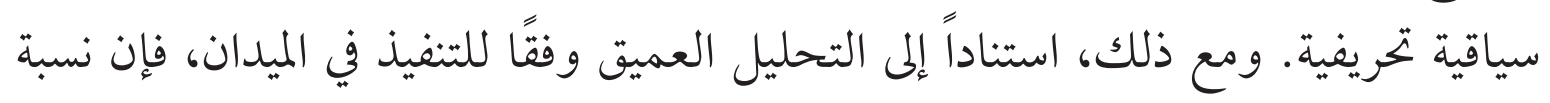
عملية التعليم أكثر الكلاسيكية من المعاصرة.

r. السياسات المأخوذة في تطوير المنهج الدراسي للغة العربية في المدرسة الثانوية الإسلامية

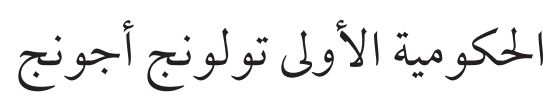

$$
\text { أ) إعطاء الفرص لمدرسي اللغة العربية لتطوير المنهج الدراسي الإني }
$$

وفي المحاولة لتطوير المنهج الدراسي، تم إعطاء الفرص لمدرسي المدرسة الثانوية الإسلامية

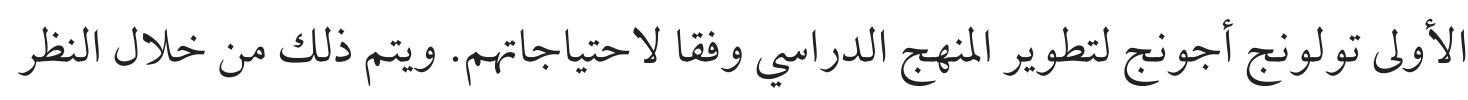

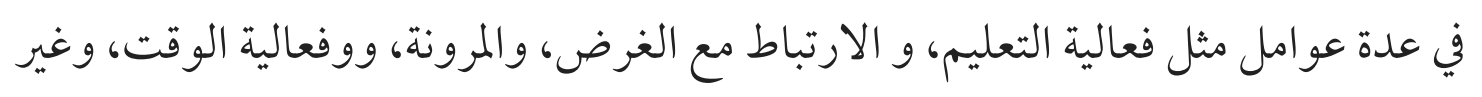
ذلك.

يمكن ملاحظة ذلك على تطوير هدف تعليم اللغة العربية. لا تزال المدرسة الثانوية

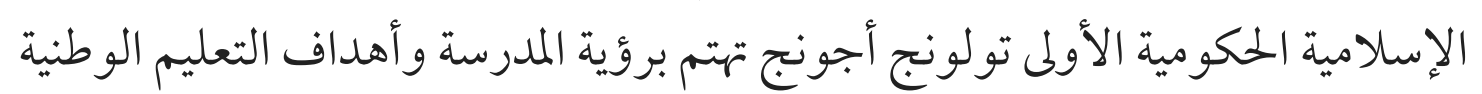

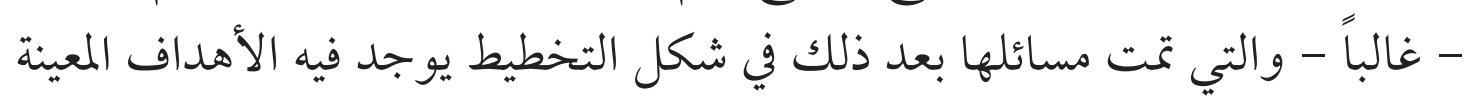
لتعليم اللغة العربية.

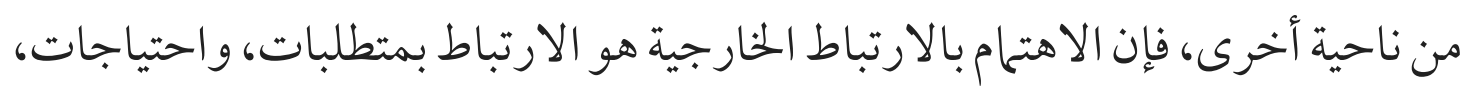

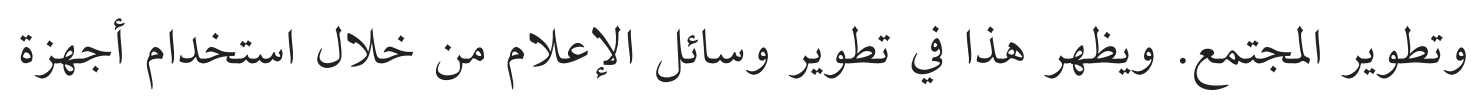

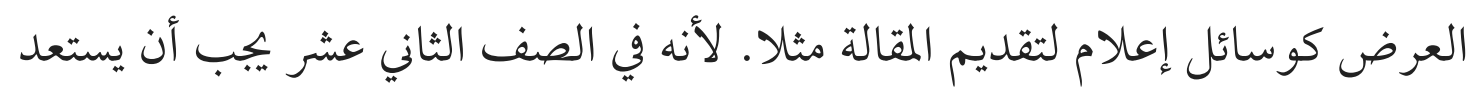

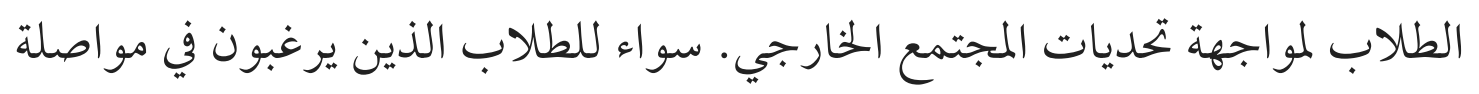

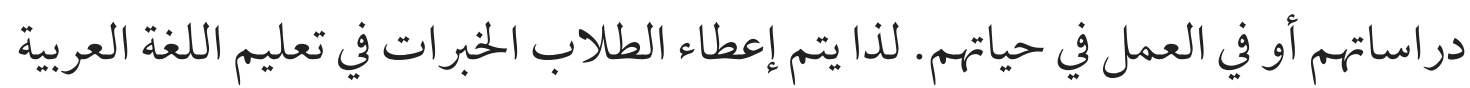
من خلال التقديم بصناعة بوور بوين. 
ويبدو أن المدرسة الثانوية الإسلامية الأولى تولونج أجونج تهتم بالمبدأ الاستمراري. أي

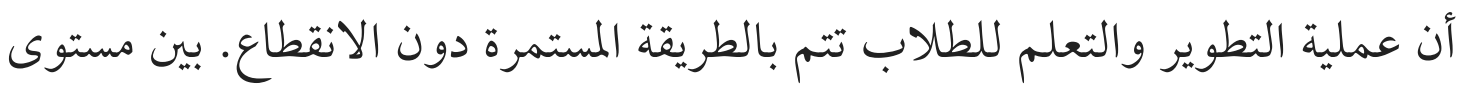
الفصل الو احد ومستوى الفصل الآخر.

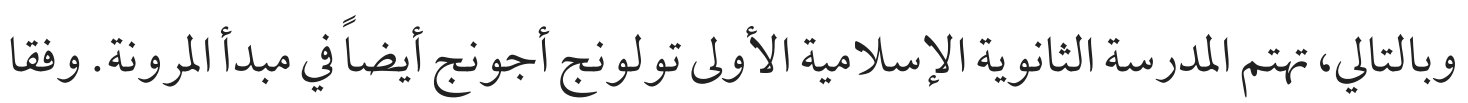

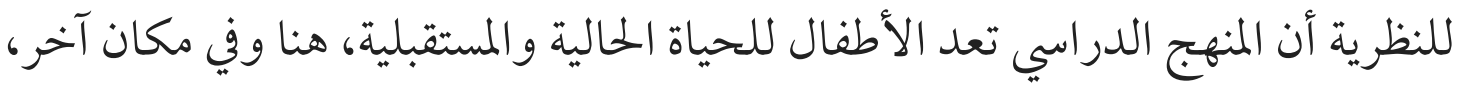

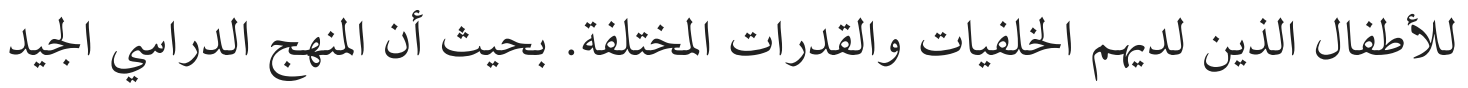

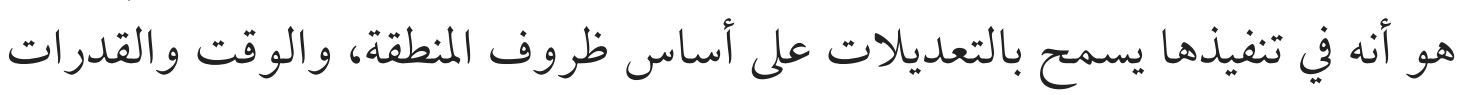

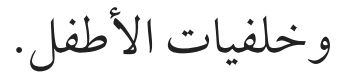

وظهر أيضا أنه في تطوير المواد باستخدام كتاب التسهيل - الذي يجتوي على اندماج المادة بين السلفية والمعاصرة- ككتاب المصاحب لكتاب مقرر من وزارة الشؤون الدينية. وذلك لتسهيل الطلاب في القراءة بسرعة. لذلك يمكن للطلاب الذين لديهم خلفية

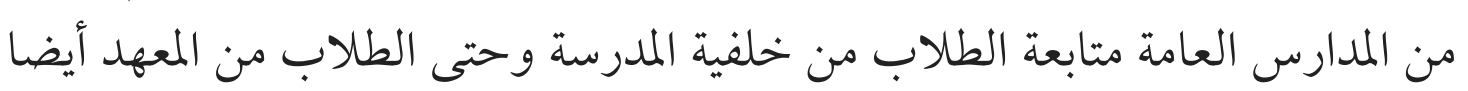
يمكنهم الحصول عليها بشكل جيد. ولذا، سيحدث توازن. لا ننسى أيضا الاهتمام بالمبادئ العملية، سهلة التنفيذ، باستخدام الأدوات البسيطة و التكاليف الرخيص. في هذه الحالة، يقوم مدرس اللغة العربية بتطوير وسيلة التعليم

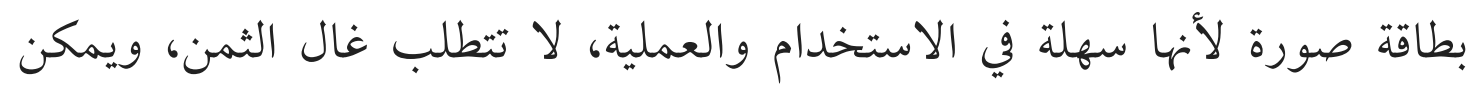
استخدامها مرة أخرى في فرصة التعليم التالية (مستوى العام الدراسي التالي). ثم المبدأ الفعالية التي لا تزال تشير إلى نجاح الهدف. وخمسة المبادئ المذكورة موحّدة في المحاولة إلى تطوير منهج اللغة العربية في المدرسة الثانوية الإسلامية الأولى تولونج المبله أجونج. أما بجال تطوير المنهج الدراسي يشتمل على خمسة المكونات وهي: الأهداف، والمو اد، و الطريقة، ووسائل التعليم والتقييم. وهذا يتفق مع نظرية مكون المنهج الدراسي التي لتئي

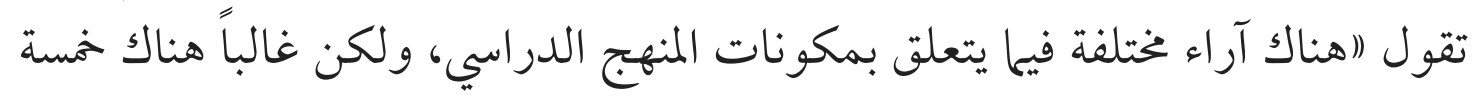

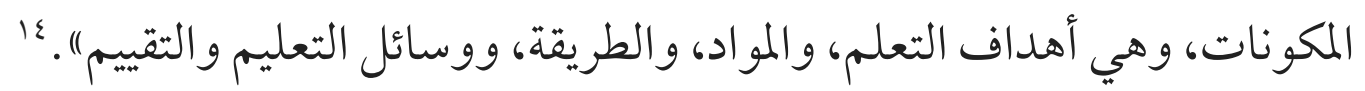


في تطوير المادة الدراسية، يبدو أن بعض المعلمين في المدرسة الثانوية الإسلامية الأولى تولونج

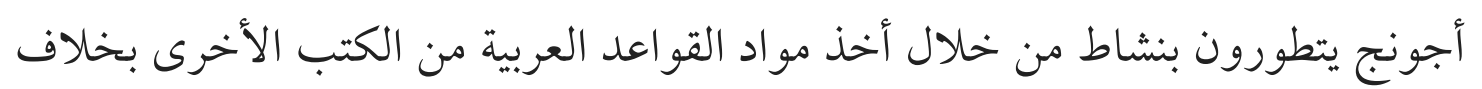

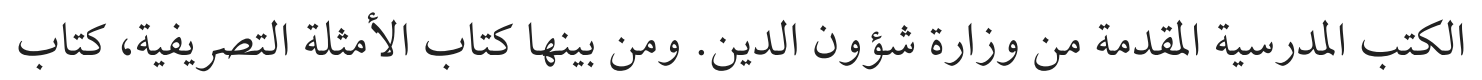

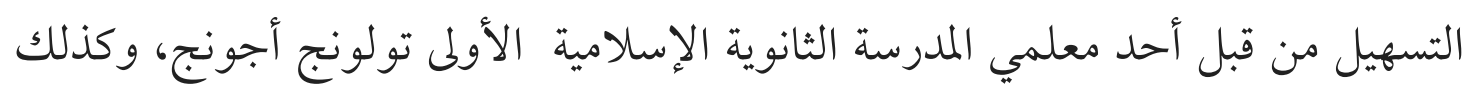

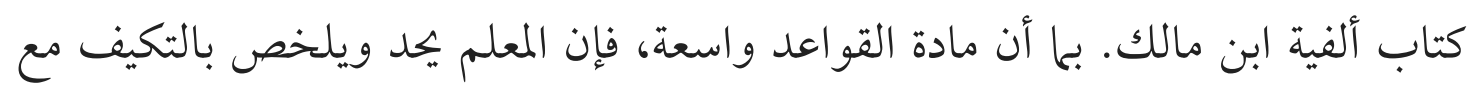
الاحتياجات المادة والمنهج الدراسي للحكومة.

إن السبب الذي يستعمل المعلم إلى استخدام كتاب التسهيل -الذي يجتوي على نصف السلف ونصف الحديثة- كدليل مصاحب لكتاب مقرر وزارة شؤون الدين هو أن يسهل على الطلاب

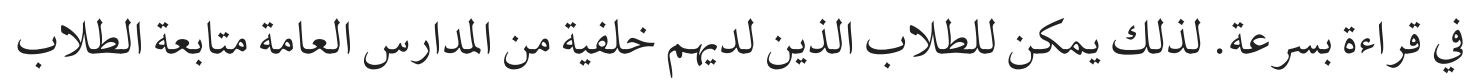

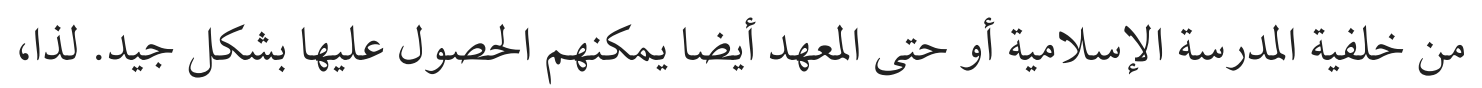
سيحدث توازن. أما أسباب تلخيص بعض المبل المو اد من كتاب السلف مثل ألفية لنحو والأمثلة

$$
\text { التصريفية إلى صرف فهو لتكثيف الدراسة المستمرة. }
$$

بالتالي، ينصح المعلمون بشدة باستخدام القواميس من أجل زيادة المفردات. وهذا ما يجعل

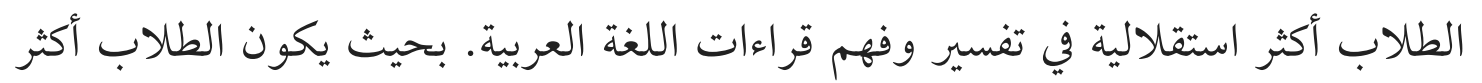

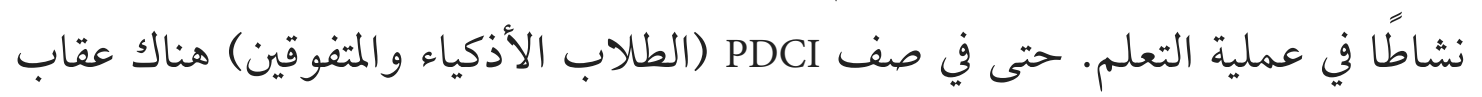

$$
\text { للطلاب الذين لا يجملون القو اميس. }
$$

من ناحية أخرى، هناك بعض المعلمين الذين لا يقومون بتطوير المواد. لأنهم يشعرون بأن

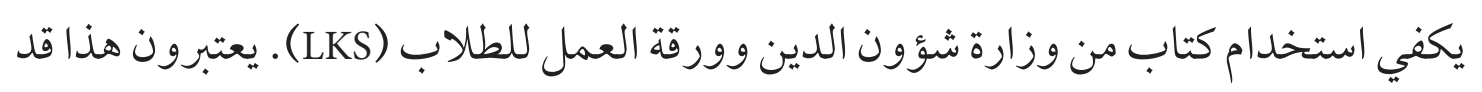
أحسن إذ يتم تنفيذ أنشطة التعليم على النحو الأمثل لتحقيق أهداف التعليم. في المحاولة لتطوير الطريقة، كل معلم لديه مجموعة متنوعة من الطرق. هناك من يستخدم

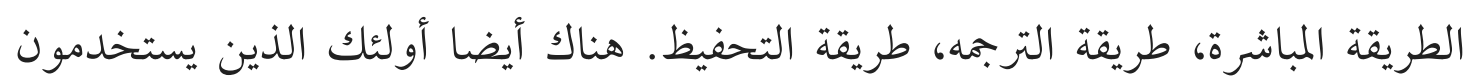

$$
\text { إستراتيجية التعلم التامّ واستراتيجيات مربعة مكسورة. } 17
$$

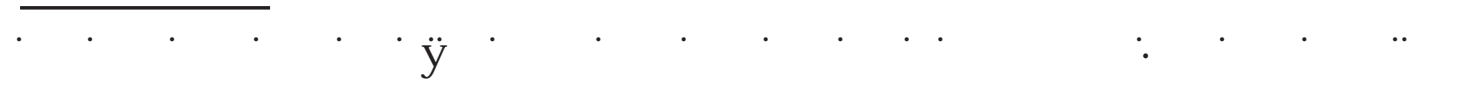

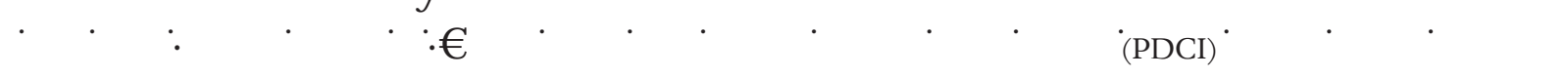

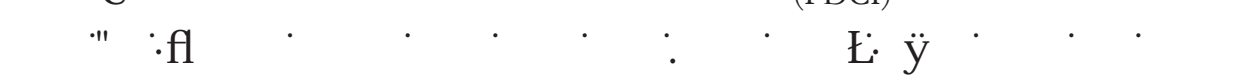

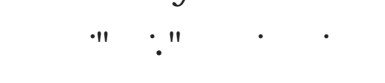


أما توفير تطوير وسائل التعليم معد أجهزة العرض في جميع أنحاء الفصل . هذا العرض مفيد جدًا للمعلمين و الطلاب في عملية التعليم. خاصة لطلبة الصف الثاني عشر المطلوب منهم تقديم مو اد قو اعد اللغة العربية استعدادا لمستوى المحاضرات ومو اجهة مطالب بعد تخرج من المدرسة. بالإضافة إلى التسهيلات التي توفرها المدرسة على شكل أجهزة عرض، قام المعلم أيضًا بتطوير وسائط برسوم توضيحية لتحفيز دافعية الطلاب.

بالتالي، تم إجر اء التقييم أيضًا باستخدام تقنيات متنوعة. فيها بينها هو نظام التسجيل (scoring). هذا هو التقييم بتخفيض نقطتين (-Y) من كل خطأ لكل قراءة. بالإضافة إلى ذلك، يتم أيضًا تقييم الطلاب شفهيًا وكتابيًا باستخدام جهاز العرض.

$$
\text { ب) تطوير كفاءة المدرس }
$$

وبناءً على المقابلة، تم تطوير كفاءات المعلمين حتى الآن من خلال عقد دورات تدريية لجميع المعلمين المو ضوعي في بداية كل مرحلة دراسية. لا يو جد تدريب خاص للمعلمين العرب الذي عقدته المدرسة الثانوية الإسلامية الحكومية الأولى تولونج أجونج. من أجل تطوير كفاءات مدرسي اللغة العربية اللاصة لا يزال المعلمون يعتمدون على التدريب

$$
\begin{aligned}
& \text { الذي تقوم به وزارة شؤون الدين المركزية. } \\
& \text { ج) تطوير كفاءة الطلاب }
\end{aligned}
$$

من أجل تطوير كفاءات الطلاب، تشكلت الأنشطة غير المنهجية كالداعم لبرنامج

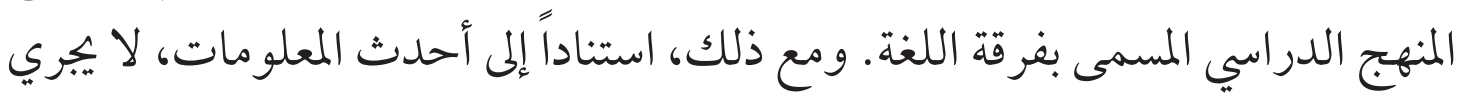
هذا النشاط اللامنهجية على النحو الأمثل. فيمكن في بداية العام الدراسي عادةً يشترك اكي

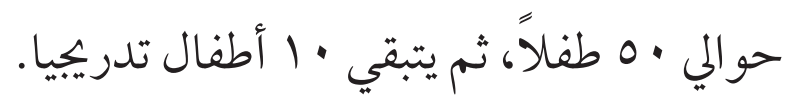
ب. ـ العوامل الداعمة والعوامل العائقة في تطوير المنهج الدراسي للغة العربية بالمدرسة

$$
\begin{aligned}
& \text { الثانوية الإسلامية الحكو مية تولونج أجونج } \\
& \text { آ) العو امل الداعمة }
\end{aligned}
$$

من العوامل الداعمة في تطوير المنهج الدراسي للغة العربية في المدرسة الثانوية الإسلامية الحكو مية تولونج أجونج هي وجود التنسيق الجيد بين المعلمين، بين المعلمين و الإداريين والمديرين وكذلك مشاركة المجتمع. ظهر هذا عندما تبادل المعلمون الأفكار وناقشوا 
مشكلات تعليم اللغة العربية. حتى ليس فقط مدرسي اللغة العربية، ولكن أيضا بين مدرسي اللغة العربية مع مدرسي اللغة الإنجليزية.

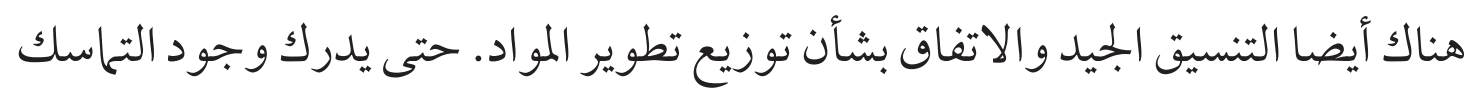

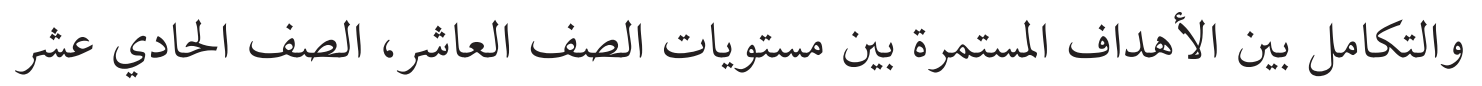

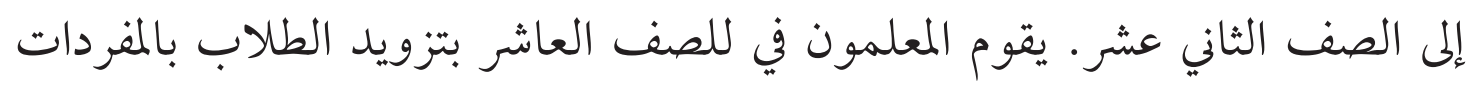

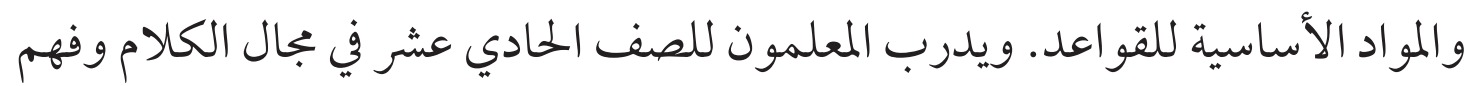
النصوص، ويمنح المعلمون للصف الثاني عشر الطلاب فرصة أكبر لأداء التقديم. لذا،

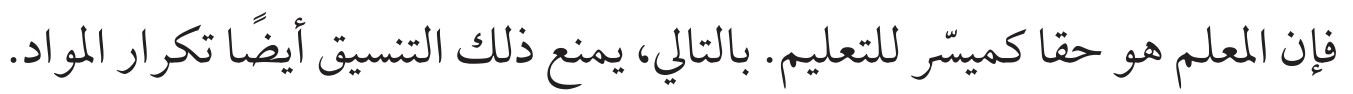
من عرض البيانات السابقة، يمكن تحليلها غالباً أن معظم العوامل الداعمة لتطوير المنهج

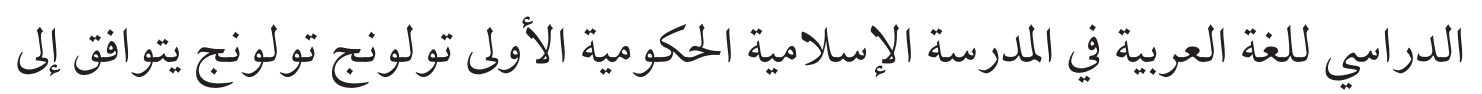
ما قالته سوكم|ديناتا في كتابه أن:

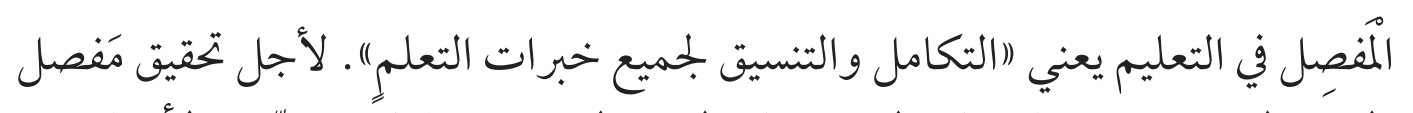

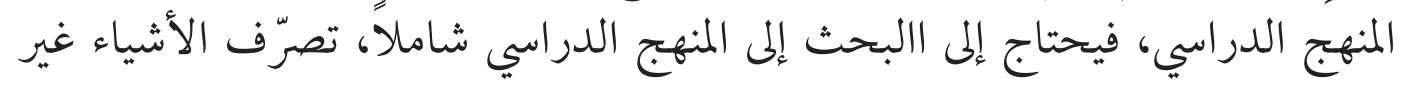

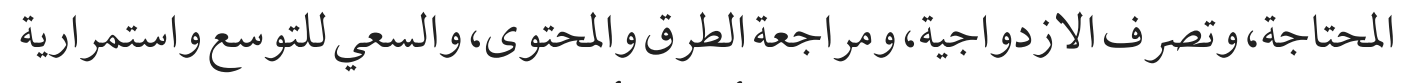

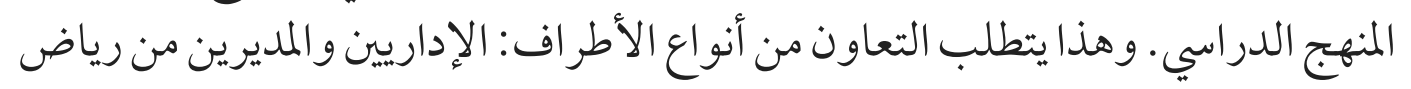

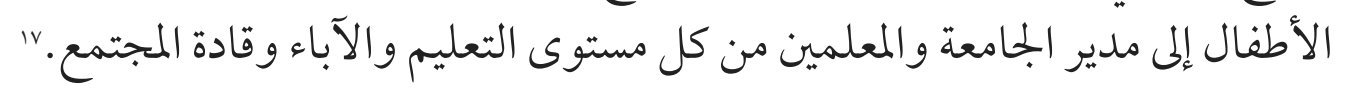

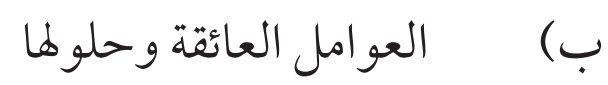
أما العو امل العائقة في تطوير المنهج الدراسي للغة العربية في المدرسة الإسلامية الحكومية

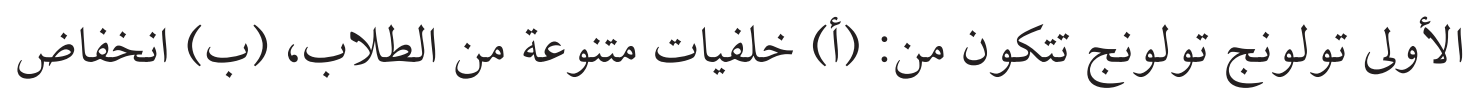

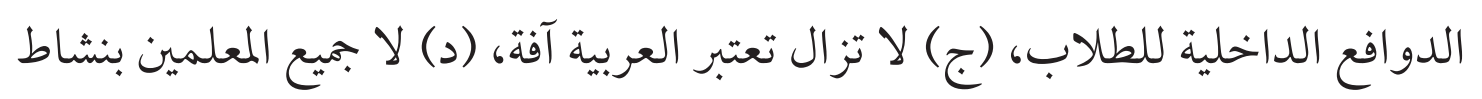

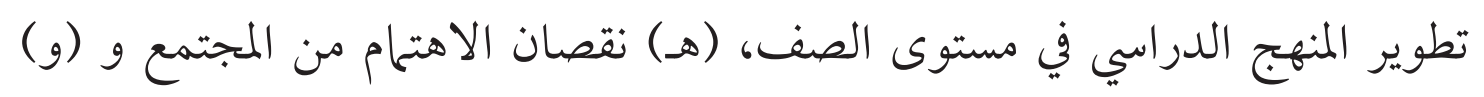

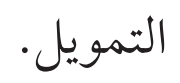
بالنسبة للعوامل العائقة لتطوير منهج الدراسي للغة العربية من ناحية بعض المعلمين

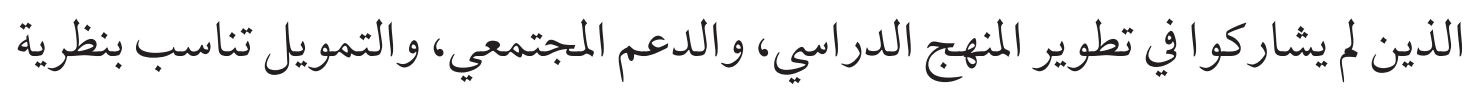

17 Nana Syaodih Sukmadinata, Pengembangan Kurikulum: Teori dan Praktek, (Bandung: Remaja Rosdakarya, 2004), h. 160-161 
في تطوير المنهج الدراسي هناك بعض العوائق. العائقة الأولى تكمن من المعلم. لم يشترك المكاء

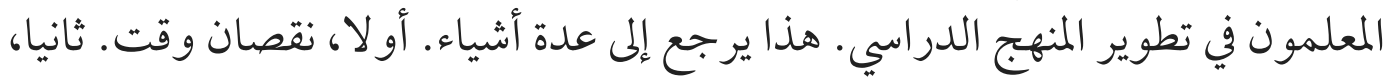

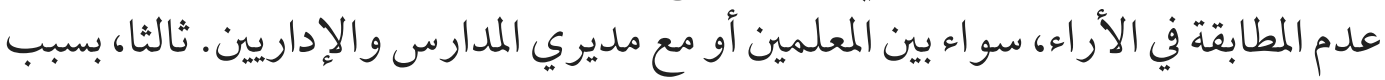

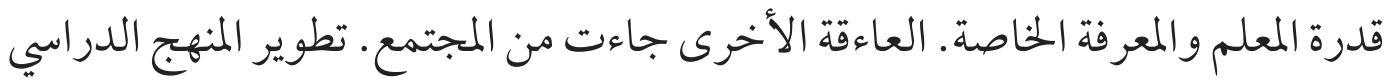

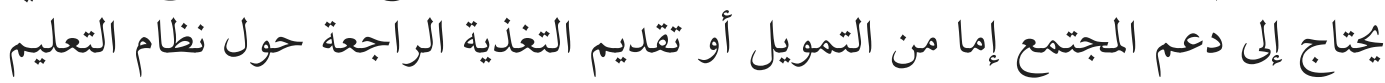

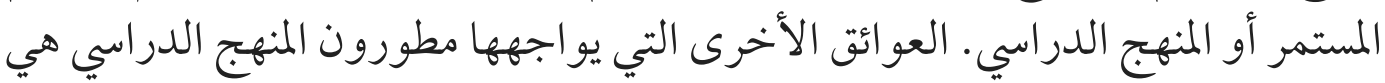

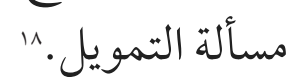

لحل الذي تقوم به المدرسة الإسلامية الحكومية الأولى تولونج تولونج للتغلب على

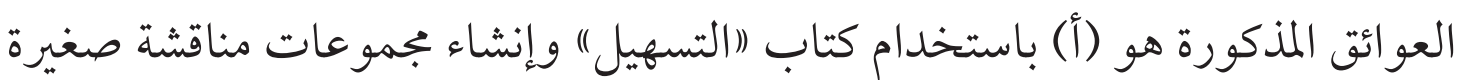

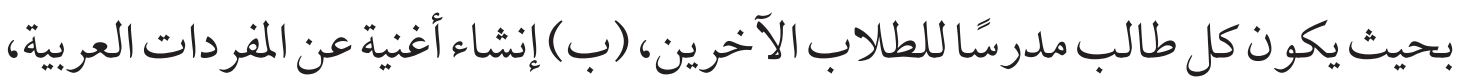
(ج) اقتر اب الطلاب بالقواميس اليدوية والرقمية، (د) عقد دورات تدريبية في بداية كل

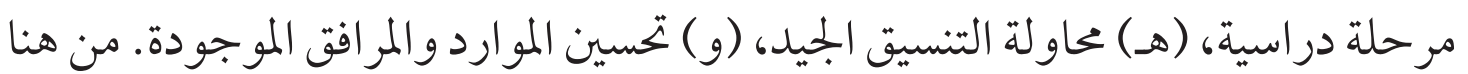

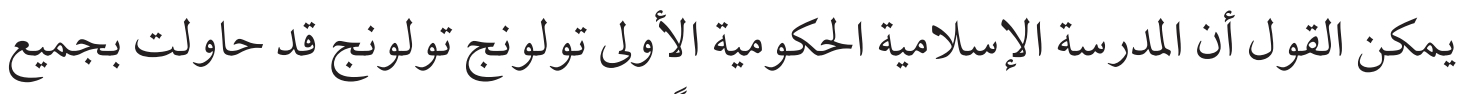

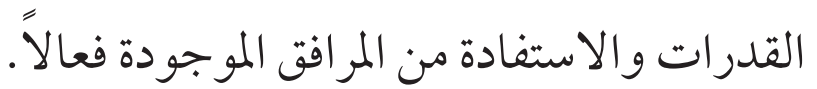

\section{aniflé}

وفيها يتعلق بأنمط المنهج الدراسي للغة العربية في المدرسة الثانوية الإسلامية الحكومية الأولى تولونج أجونج، يدعم الباحثان المحاولات لتطوير المنهج الدراسي للغة العربية في

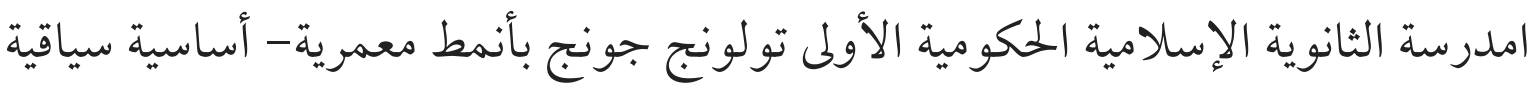
تحريفية (Perenial-Esensialis Kontekstual Falsifikatif). التي تسعى هذه الأنمط بأخذ الطريقة الوسطية بين العودة إلى الماضي عن طريق وضع سياق واختبار التحريف وتطوير الأفكار في

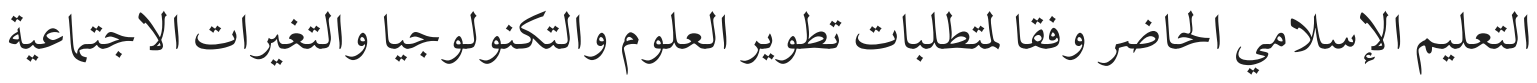
القائمة.

ومع ذلك، من المستحسن جمع بين الأنمط الرابعة والأنمط الخامسة أي إعادة البناء 
الاجتماعي على أساس التوحيد (Rekonstruksi Sosial Berlandasakan Tauhid). هذا هو التأكيد على الموقف الاستباقي، حتى تكون مهمة التعليم هي مساعدة الناس على أن يصبحوا

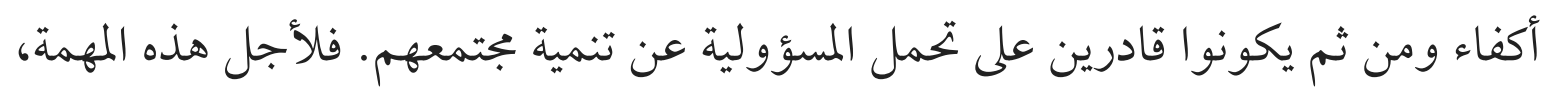
فإن وظيفة التربية الإسلامية هي محاولة تنمية إبداع الطلاب، وإثراء كنوز الثقافة البشرية،

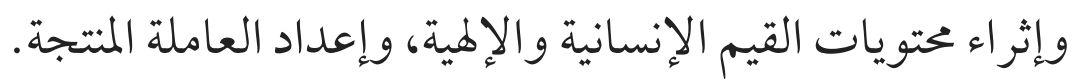

بحيث تتمّ المحاولة إلى الحفاظ على القيم (الإهية والبشرية) موازنة بإبداع الطلاب، إبها

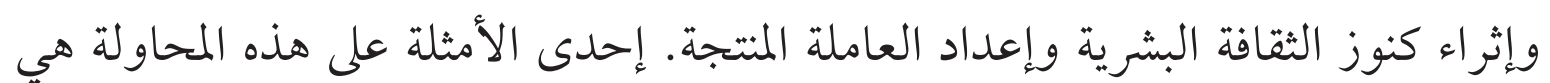

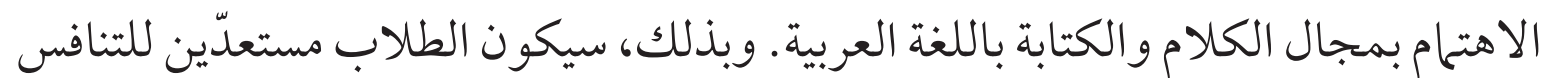
في الحياة من القرن الحادي و العشرين.

فيما يتعلق بالسياسات التي اتخذتها المدرسة الثانوية الإسلامية الحكومية الأولى تولونج

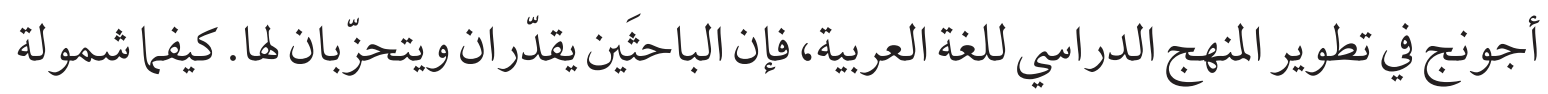

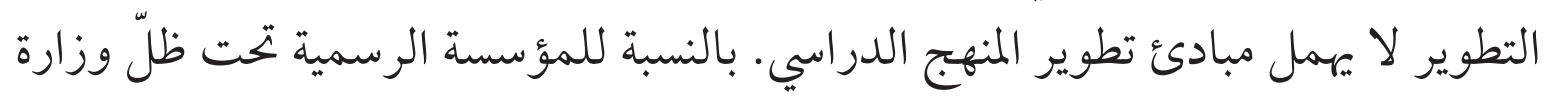
شؤون الدين، ويعني غير المعهد، فإن المدرسة الثانوية الإسلامية الحكومية الأولى تولونج

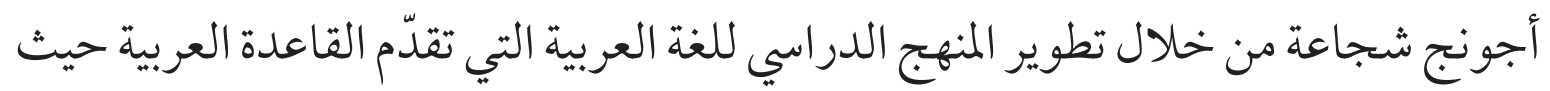

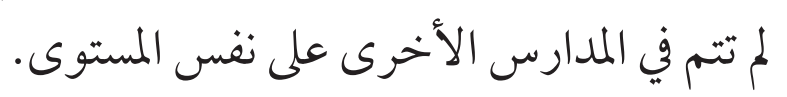

ارتباطاً بالعوامل الداعمة والعائقة عن تطوير المنهج الدراسي للغة العربية في المدرسة

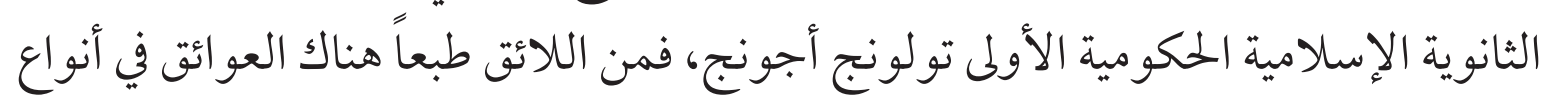

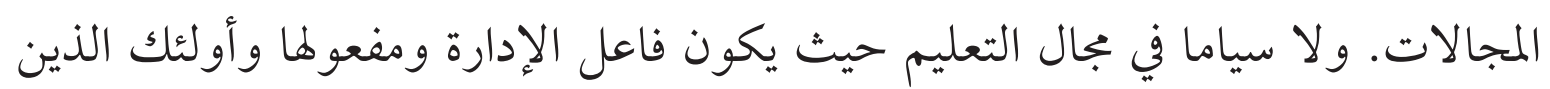
يدارون هم بشر لديهم اتجاهات خاصة وميول شخصية. ومع ذلك، فإن المدرسة الثانوية

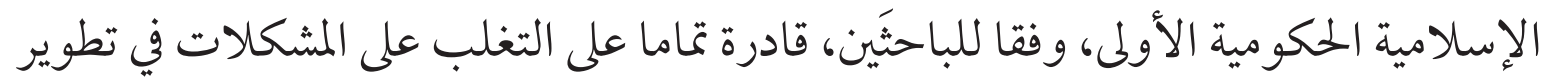

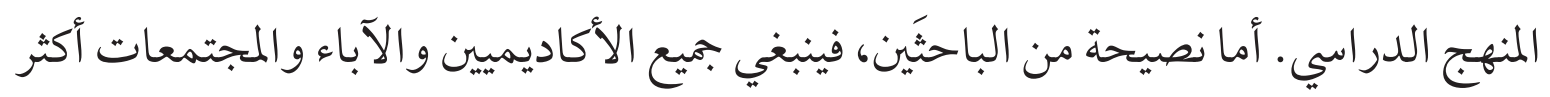
الاهتحام بتعليم اللغة العربية.

\section{d̆ $\mathrm{R} z$}

من المباحثة السابقة، فكانت الخلاصة كما يالي: 
ا. ـ أنمط المنهج الدراسي في المدرسة الثانوية الإسلامية الحكومية الأولى تولونج أجونج هي أنمط معمرية- أساسية سياقية تحريفية.

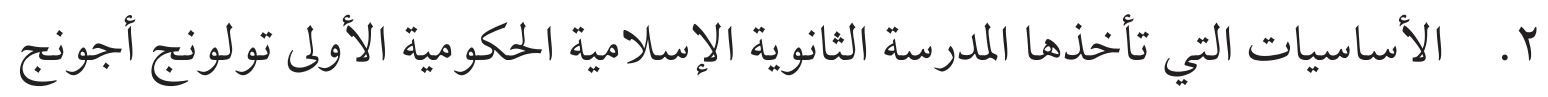

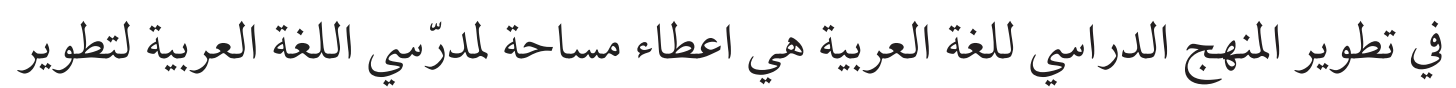

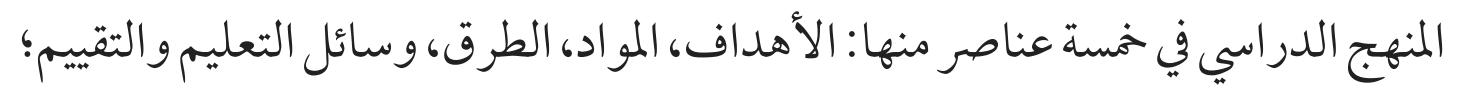
تنمية كفاءة المدرّس بالثدريب في بداية كل مرحلة دراسية ووجود أنشطة لا منهجية (فرقة اللغة) لتطوير كفاءة الطلاب.

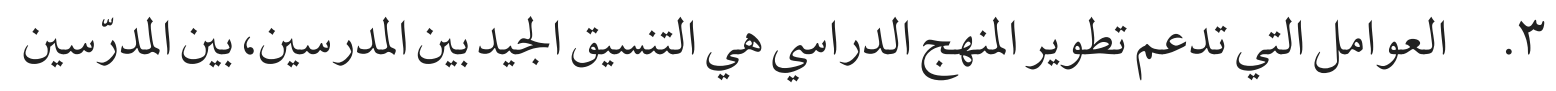

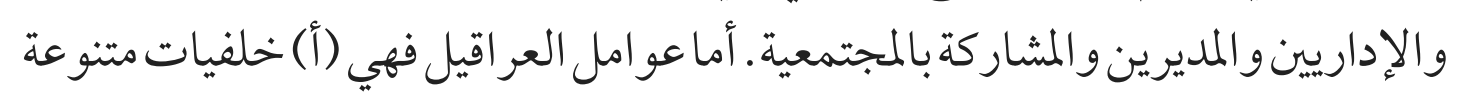

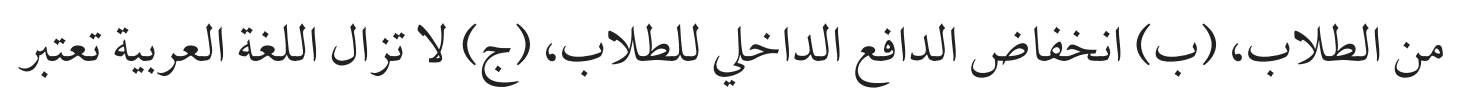

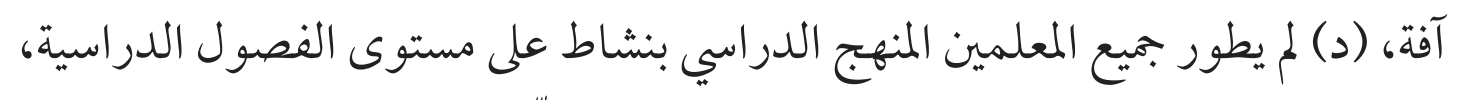

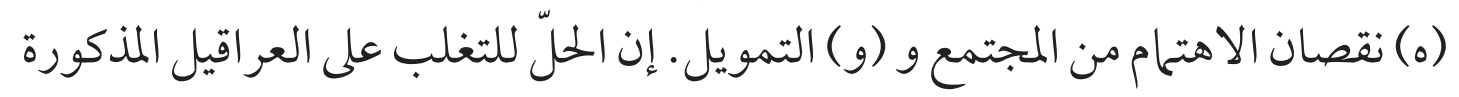

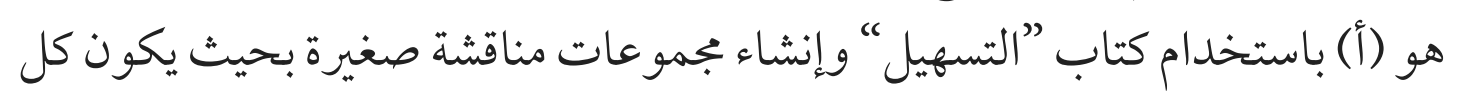

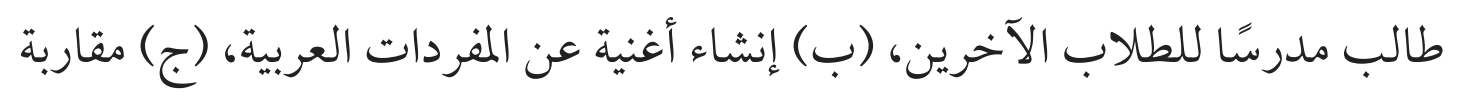

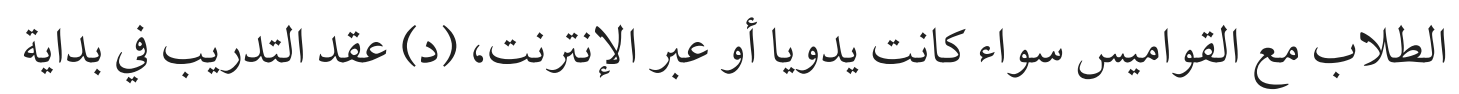
كل مرحلة دراسية، (هـ) محاولة التنسيق، (و) تحسين المواردو المر افق الموجودة. 


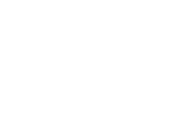

Achmad, Bani. 2014. “Tipologi Filsafat Pendidikan Islam dan Implementasinya dalam

Pengembangan Kurikulum” dalam jurnal Edukasi vol. 02 no. 01, Juni 2014.

Tulungagung: STAI Muhammadiyah.

Azwar, Saifudin Metode Penelitian. Yogyakarta: Pustaka Pelajar Offset, 2002.

Hermawan, Acep 2011. Metodologi Pembelajaran Bahasa Arab. Bandung: Remaja Rosdakarya.

Meleong, Lexy J. 2011. Metodologi Penelitian Kualitatif. Bandung: Remaja Rosdakarya.

Muhaimin. 2005. Pengembangan Kurikulum Pendidikan Agama Islam di Sekolah, Madrasah, dan Perguruann Tinggi. Jakarta: Rajawali Pers.

Sukmadinata, Nana Syaodih. 2004. Pengembangan Kurikulum: Teori dan Praktek. Bandung: Remaja Rosdakarya.

Tholchah, Moch. 2015. "Filsafat Pendidikan Islam: Konstruksi Tipologis dalam Pengembangan Kurikulum” dalam Jurnal Tsaqafah vol. II no. 2, November 2015. Gontor: Unida

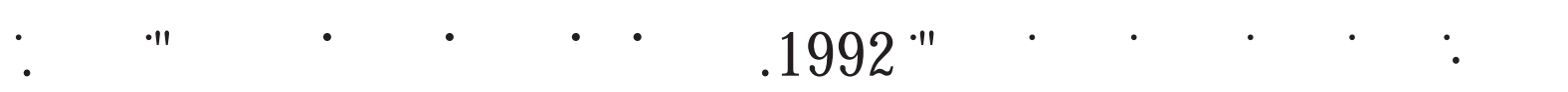

पatity

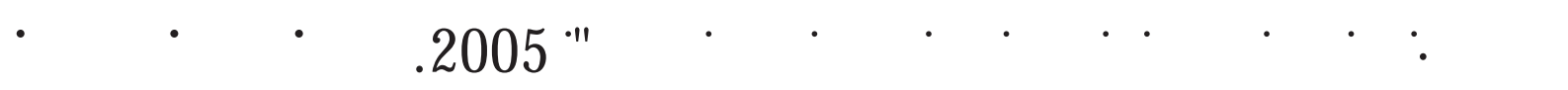

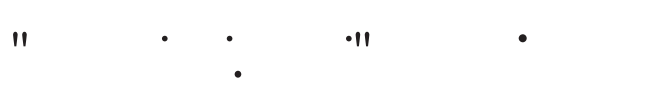

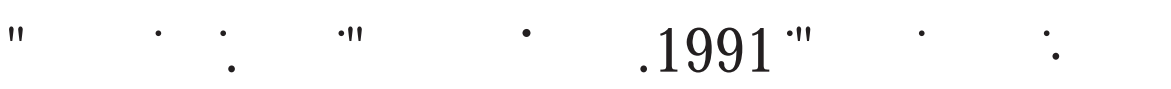

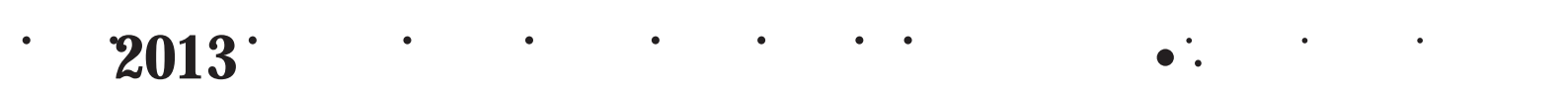

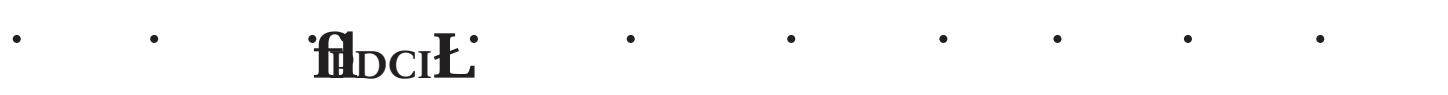

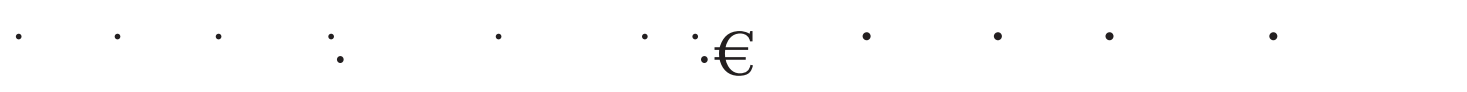

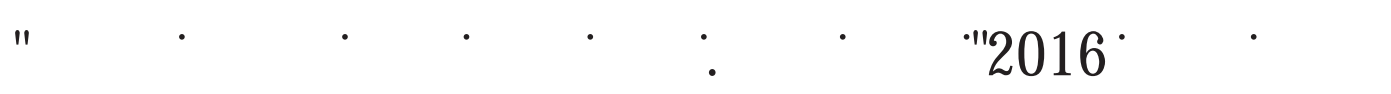

